\title{
Behavioural variation and plasticity along an invasive ant introduction pathway
}

\author{
Antoine Felden $^{1}$ (D) | Carolina I. Paris ${ }^{2}$ (D) | David G. Chapple ${ }^{3}$ (D) | John Haywood ${ }^{4}$ | \\ Andrew V. Suarez ${ }^{5}$ (D) | Neil D. Tsutsui ${ }^{6}$ (D) | Philip J. Lester ${ }^{1}$ (D) | Monica A. M. Gruber ${ }^{1}$ (D) \\ ${ }^{1}$ Centre for Biodiversity and Restoration Ecology, School of Biological Sciences, Victoria University of Wellington, Wellington, New Zealand; ${ }^{2}$ Departamento \\ Ecología, Genética y Evolución, Universidad de Buenos Aires, Buenos Aires, Argentina; ${ }^{3}$ School of Biological Sciences, Monash University, Clayton, Victoria, \\ Australia; ${ }^{4}$ School of Mathematics and Statistics, Victoria University of Wellington, Wellington, New Zealand; ${ }^{5}$ Department of Animal Biology and Department \\ of Entomology, University of Illinois, Urbana, Illinois and ${ }^{6}$ Department of Environmental Science, Policy and Management, University of California - Berkeley, \\ Berkeley, California
}

Correspondence

Antoine Felden

Email: antoine@felden.fr

Funding information

Royal Society of New Zealand Marsden,

Grant/Award Number: 13-VUW-038

Handling Editor: Julian Resasco

\section{Abstract}

1. Once established in new areas, introduced species may exhibit changes in their biology due to phenotypic plasticity, novel selection pressures and genetic drift. Moreover, the introduction process itself has been hypothesised to act as a selective filter for traits that promote invasiveness.

2. We tested the hypothesis that behaviours thought to promote invasiveness-such as increased foraging activity and aggression-are selected for during invasion by comparing traits among native and introduced populations of the widespread Argentine ant (Linepithema humile).

3. We studied Argentine ant populations in the native range in Argentina and in three invaded regions along an introduction pathway: California, Australia and New Zealand. In each region, we set up 32 experimental colonies to measure foraging activity and interspecific aggression in a subset of the study regions. These colonies were subject to experimental manipulation of carbohydrate availability and octopamine, a biogenic amine known to modulate behaviour in insects, to measure variation in behavioural plasticity.

4. We found variation in foraging activity among populations, but this variation was not consistent with selection on behaviour in relation to the invasion process. We found that colonies with limited access to carbohydrates exhibited unchanged exploratory behaviour, but higher exploitation activity and lower aggression. Colonies given octopamine consistently increased foraging behaviour (both exploration and exploitation), as well as aggression when also sugar-deprived. There was no difference in the degree of behavioural response to our experimental treatments along the introduction pathway.

5. We did not find support for selection of behavioural traits associated with invasiveness along the Argentine ant's introduction pathway or clear evidence for an association between the introduction process and variation in behavioural plasticity. These results indicate that mechanisms promote behavioural variation in a similar fashion both in native and introduced ranges. Our results challenge the 
assumption that introduced populations always perform better in key behavioural

traits hypothesised to be associated with invasion success.

\section{KEYWORDS}

behavioural plasticity, behavioural variation, biological invasions, introduction pathway,

invasive species

\section{1 | INTRODUCTION}

Species transported by humans often undergo population bottlenecks because the number of initial founders is typically low, resulting in introduced populations harbouring a subset of the genetic diversity of native populations (Dlugosch \& Parker, 2008; Sakai et al., 2001; Tsutsui, Suarez, Holway, \& Case, 2000). Despite the potential problems associated with reduced genetic variation and a lack of local adaptation, introduced populations often outperform native populations in key traits associated with growth and reproduction (Parker et al., 2013), creating a paradox for their success (Allendorf \& Lundquist, 2003; Sax \& Brown, 2000). Many mechanisms have been proposed to explain the success of invasive species, including natural enemy release or rapid evolution associated with novel selection pressures and genetic drift (Kolar \& Lodge, 2001; Sakai et al., 2001; Torchin, Lafferty, Dobson, McKenzie, \& Kuris, 2003; Whitney $\&$ Gabler, 2008). A possible factor to explain the success of invasive species is that introduced populations must pass through a succession of critical stages (i.e. association with humans, transportation, establishment and spread) with each stage having specific barriers that may filter out maladaptive phenotypes (Blackburn et al., 2011; Chapple, Simmonds, \& Wong, 2012; Sakai et al., 2001; Suarez \& Tsutsui, 2008). Under this scenario, the introduction process leads to newly established populations being nonrandom subsets of native populations by promoting traits associated with invasion success. In this study, we investigated behavioural variation and plasticity in native and introduced Argentine ant populations to test the hypothesis that the introduction process acts as a filter, leading to the selection of traits that promote invasiveness.

Behaviour is a key predictor of invasion success in animals, and behavioural traits that are likely to influence the competitive abilities of an invasive species are diverse (reviewed in Chapple et al., 2012; Holway \& Suarez, 1999; Phillips \& Suarez, 2012). In social insects, different colonies can vary substantially in many traits and be subjected to natural selection (Gordon, 2013; Jandt \& Gordon, 2016; Jandt et al., 2014). Activity, aggressiveness and boldness are all thought to be important factors in promoting fitness in a wide range of species (Biro \& Stamps, 2008; Smith \& Blumstein, 2008). These behaviours may also promote invasiveness, as suggested for the delicate skink compared to the closely related but noninvasive garden skink (Chapple, Simmonds, \& Wong, 2011). Different behavioural traits may influence invasion success at different stages of the introduction process, and a single trait can have either positive and/or negative effect on survival depending on the stage considered (Chapple \& Wong, 2016; Chapple et al., 2012). In new environments, increased foraging activity and aggression could translate into increased foraging success through faster resource discovery and exploitation. Increased behavioural plasticity could be also favoured in invaders, especially in early stages of an invasion by promoting the spread to novel habitats in a new range (Wright, Eberhard, Hobson, Avery, \& Russello, 2010). The behaviours associated with foraging and aggression are therefore good candidates to test our hypothesis by measuring postestablishment variation and plasticity in behavioural traits along an introduction pathway as a species is introduced from one location to another.

The Argentine ant (Linepithema humile) is a global invader that can have damaging effects on agriculture, ecosystems and human activities (Holway, Lach, Suarez, Tsutsui, \& Case, 2002). Outside its native range in the Paraná River basin in South America, the ant was first recorded on the Atlantic island of Madeira in the 1850s (Wetterer, Wild, Suarez, Roura-Pascual, \& Espadaler, 2009) and its likely invasion pathway has been partially reconstructed from historical records as well as behavioural and genetic data (Tsutsui, Suarez, Holway, \& Case, 2001). Half a century later, the ant was detected in warm temperate and Mediterranean regions, including North America and Southern Europe (Vogel, Pedersen, Giraud, Krieger, $\&$ Keller, 2010), and from the latter likely invaded Australia in the 1930s (Suhr, O'Dowd, McKechnie, \& Mackay, 2011). From Australia, it then colonised New Zealand in the 1990s (Corin, Lester, Abbott, \& Ritchie, 2007). Population genetics and behavioural data altogether show evidence for successive introductions from a single origin in Argentina (Van Wilgenburg, Torres, \& Tsutsui, 2010; Vogel et al., 2010). The well-documented successive introductions of a single Argentine ant population from its native range to New Zealand make it an ideal system to test the hypothesis of trait selection during the introduction process.

We examined behavioural variation of Argentine ants in four regions along an invasion pathway: its native range in Argentina and three locations invaded by fragments of the same "global supercolony" (California, Australia and New Zealand; Van Wilgenburg et al., 2010). In each region, we measured foraging behaviour (exploration activity and exploitation of a food source) of experimental colonies given a novel foraging arena. We also quantified aggressive behaviour towards local ants in a subset of the study regions. If 
selection for increased foraging activity and aggression has occurred as Argentine ants were introduced from one region to another, we predict that relative to native populations, colonies from introduced populations will take less time to explore a novel environment, recruit more workers to a resource and act more aggressively towards heterospecifics.

Behavioural plasticity is thought to be associated with invasion success (Chapple \& Wong, 2016). Artificially manipulating modulators of behaviour may provide insights on the extent of behavioural plasticity in different Argentine ant populations. We therefore also subjected colonies to an experimental manipulation of carbohydrate availability (high and low sugar) and octopamine (OA), both of which can influence insect behaviour. OA is a major biogenic amine in invertebrates known to influence foraging behaviour and aggression in social insects, among many other neuroactive compounds such as dopamine (Kamhi, Arganda, Moreau, \& Traniello, 2017). In honeybees, the role of OA in modulating division of labour and foraging activity is well established (Schulz, Barron, \& Robinson, 2002; Schulz \& Robinson, 2001). OA can promote aggressive behaviour in ants (e.g. Aonuma \& Watanabe, 2012; Cuvillier-Hot \& Lenoir, 2006; Kamhi, Nunn, Robson, \& Traniello, 2015; Vander Meer, Preston, \& Hefetz, 2008), though there is less known about the role of OA in foraging behaviour (but see Cuvillier-Hot \& Lenoir, 2006; Smith, Muscedere, Seid, Traniello, \& Hughes, 2013; Seid \& Traniello, 2005). If $O A$ is associated with modulation of foraging behaviour and aggression in Argentine ants, we predicted that OA-treated ants will be more exploratory and aggressive. Similarly, carbohydrate availability can increase ant activity and aggression (e.g. Grangier \& Lester, 2014; Grover, Kay, Monson, Marsh, \& Holway, 2007), and we predict colonies with high sugar availability will also be more exploratory and aggressive. To determine how the process of introduction could influence behavioural variation and plasticity, we tested two

\section{(a) Locations of study regions}

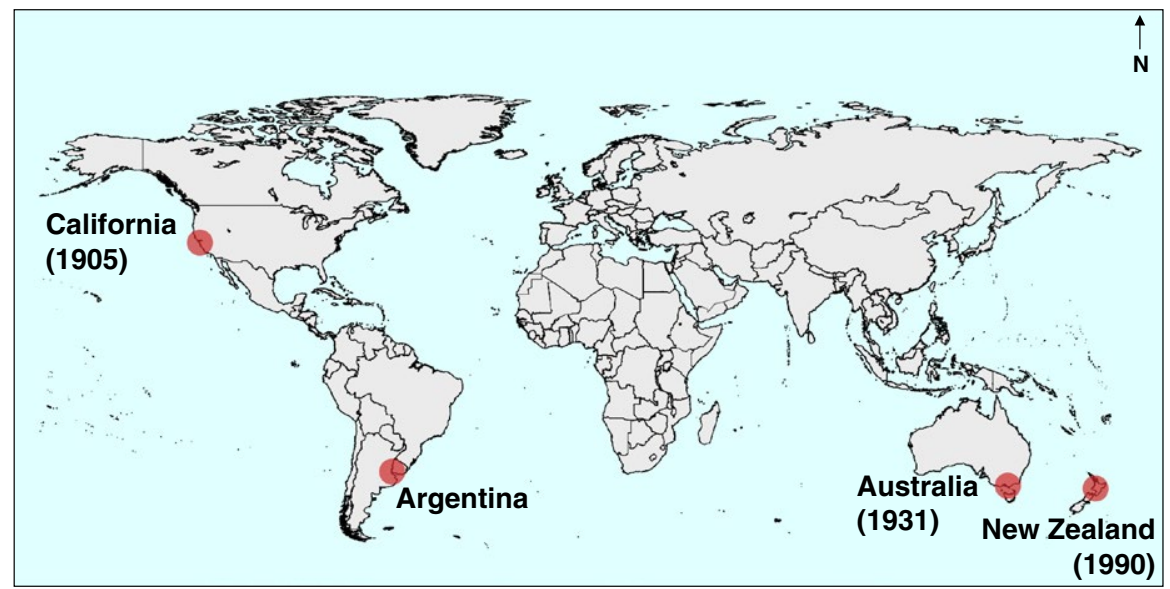

(b) Argentina

(c) California
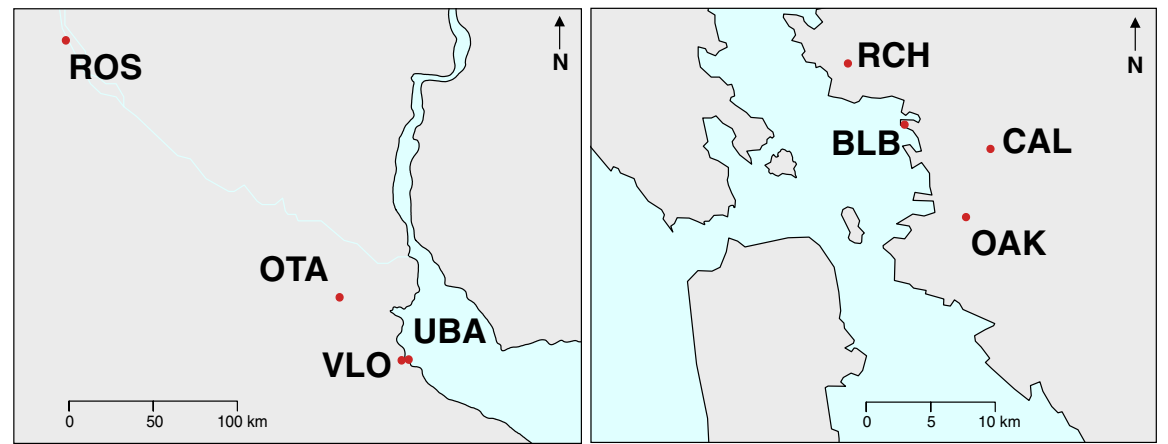

(d) Australia

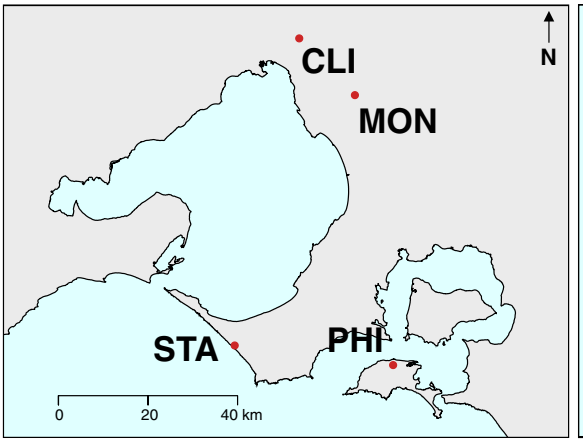

(e) New Zealand

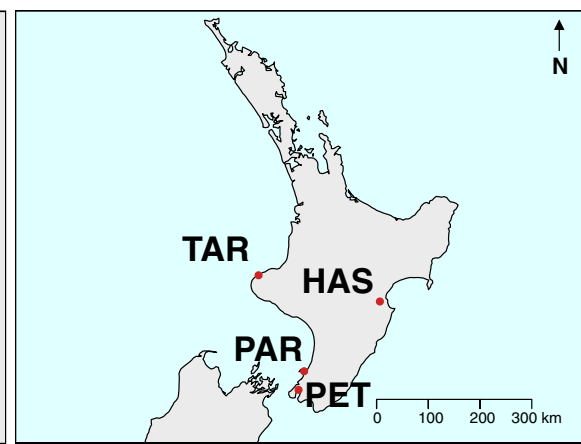

FIG URE 1 (a) Regional populations included in the study. Earliest record of the Argentine ant in the three invaded regions are given in brackets (Wetterer et al., 2009). Regional locations of the collection sites in (b) Argentina, (c) California, (d) Australia and (e) New Zealand. Site names and descriptions are given in Supporting Information Table S1 [Colour figure can be viewed at wileyonlinelibrary.com]

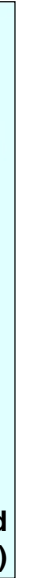


(a) Exploration of a novel environment

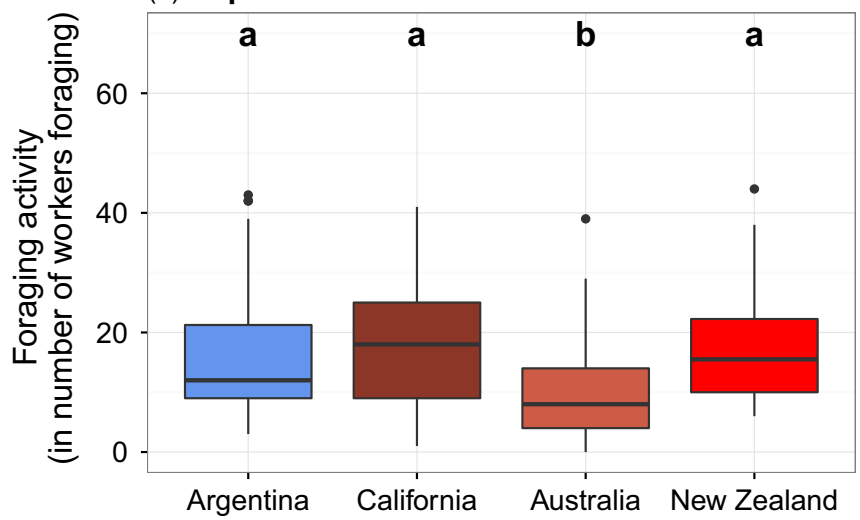

(b) Exploitation of a new food source

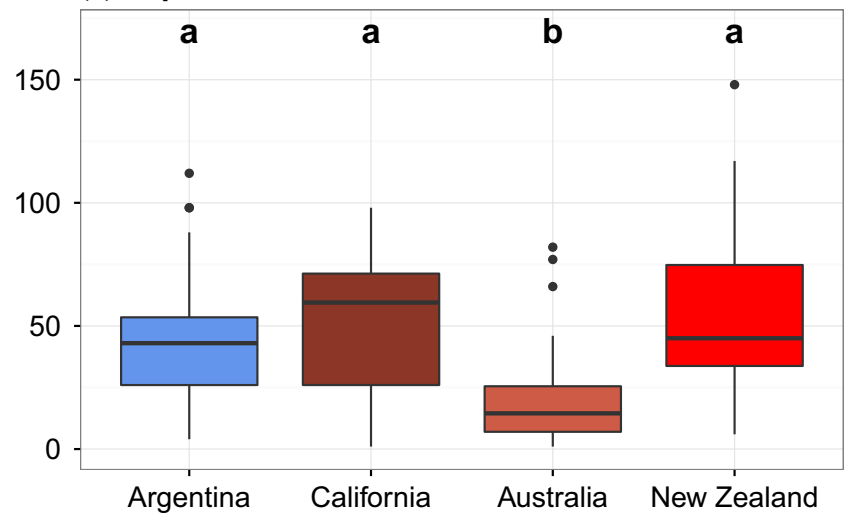

(c) Exploitation of a new food source: variation among collection sites

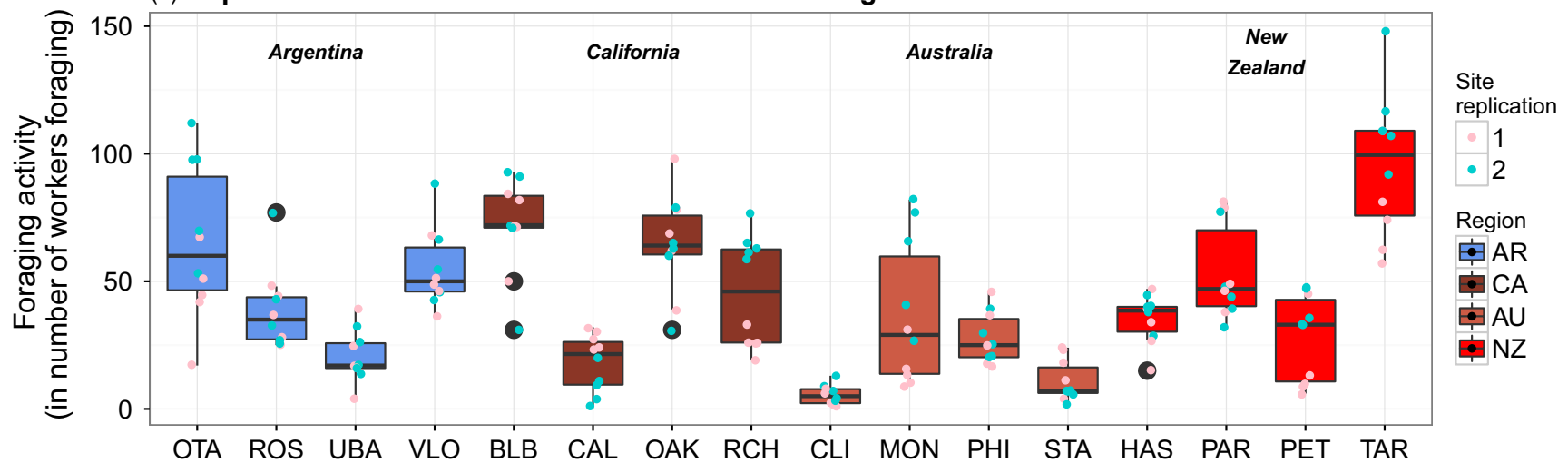

FIGURE 2 Colony-level foraging activity was very variable, but there was no directional variation along the introduction pathway. (a) Colony-level foraging activity when exploring a new environment that offered no resource. (b) Colony-level foraging activity in the context of the exploitation of a newly discovered food source in a new environment. (c) Detailed plotting of (b) with data broken down per site to illustrate variability among site within region and within site. Data are shown for control groups only ( $n=8$ colonies per region, with eight observations for each colony during the exploration phase and five during the exploitation phase) to show innate variation in foraging activity along the introduction pathway and showed no consistent directional variation along the introduction pathway with only significantly lower exploitation activity in Australia. In plots (a) and (b), different letters (i.e. a, b) indicate significant differences within phases. Outliers are represented with black dots (i.e. beyond 1.5 interquartile lower and upper ranges) or circled in black in plot (c). Site replication in plot (c) identifies the two experimental colony replicates per site. Site name abbreviations are described in Supporting Information Table S1 [Colour figure can be viewed at wileyonlinelibrary.com]

alternate hypotheses. If an increase in foraging activity and aggression in introduced populations stems from upregulated signalling in the ant's octopaminergic system, then we predict the ants will be less responsive to $\mathrm{OA}$ experimental manipulations along the introduction pathway. Alternatively, we predict an increase in the behavioural response to $\mathrm{OA}$ supplementation and carbohydrate scarcity if behavioural plasticity is enhanced in introduced populations.

\section{2 | MATERIALS AND METHODS}

\section{1 | Sampling and experimental colonies maintenance}

We studied Argentine ant populations in their native range in Argentina and in three introduced regions-California, Australia and New Zealand (Figure 1a). In Argentina, we chose four populations near Rosario and Buenos Aires as they are the hypothesised source for introduced populations (Tsutsui et al., 2001). In each region, ants were collected within a week of initiating the experiment at four different sites separated by a distance ranging from 5 to $300 \mathrm{~km}$, in summer (Figure 1b-e; Supporting Information Table S1). A minimum of 20,000 adult workers were collected at each site. In the laboratory, colonies were then isolated from soil material by connecting the collection box to a clean one using a metal wire and slowly flooding the former to encourage migration (Scholes \& Suarez, 2009). We set up eight experimental colonies per site, each comprising 1,200 workers, four queens and a small amount of brood for a total of 32 experimental colonies per study region. Two experimental colonies per site were assigned to each treatment (referred as "site replication" in Figure 2). To equalise proportions of foragers versus within-nest workers, we collected ants from intermediary boxes that contained well-mixed groups of workers and offered no shelter for behavioural subgroups (e.g. nurses or guards). Colonies were housed in nest tubes placed in 
$30 \times 30 \times 12 \mathrm{~cm}$ plastic boxes and maintained in standard conditions throughout the study regions (see Supporting Information Figure S1).

Experimental treatments were designed to investigate the effect of $O A$ and sugar availability on the Argentine ant behaviour in a $2 \times 2$ factorial design (Table 1). Ants were fed with corresponding experimental treatment $16 \mathrm{hr}$ before the experiments of the next day. Oral OA treatment has been shown to effectively increase OA brain levels in honeybees (Barron, Maleszka, Vander Meer, Robinson, \& Maleszka, 2007), and similar OA administration protocols to ours have been shown to influence ant behaviour (e.g. Vander Meer et al., 2008). To estimate the exposure of the ants to OA in our experimental treatments at the time of the assays, we sampled workers in New Zealand 16 hours after the last experimental feeding to perform a high-performance liquid chromatography (HPLC) quantification of OA on pooled heads (Supporting Information Method S1, Figure S2). Although full-head OA titration likely includes residual OA in the ants' mouthparts and oesophagus, it reflects exposure to exogenous OA.

\section{2 | Behavioural assays}

\subsection{1 | Foraging assays}

Foraging assays measured both the exploration of a novel structure and the exploitation of a food source. The novel structure was an artificial wooden tree (Supporting Information Figure S1) made of a $12 \times 12 \mathrm{~cm}$ base mounted with a $60 \mathrm{~cm}$ trunk $(10-\mathrm{mm}$-diameter wooden dowel) branched with 11 horizontal sticks every $5 \mathrm{~cm}$ (12$\mathrm{cm}$ wooden skewer, $2 \mathrm{~mm}$ diameter). Experimental colonies were given access to the tree daily during the course of the 20-day experiment by placing it in their foraging area every day, at the start of the assay. Assays were consistently performed in the morning, at 10 a.m., by a single observer under standard conditions (Supporting Information Figure S1). We recorded foraging activity by counting the ants present on the tree trunk and branches every $10 \mathrm{~min}$ for an hour. In most cases, foraging activity started to decrease after 20 min (Supporting Information Figure S3). Therefore, to capture foraging behaviour in the context of a novel environment, we only analysed data for the first 20 minutes.

TABLE 1 Composition of the experimental treatments, designed to study the behavioural effects of octopamine (OA) and sugar availability. Experimental colonies were randomly assigned to a treatment and had daily access to $1 \mathrm{ml}$ of corresponding solution plus a mealworm (Tenebrio molitor) $(\approx 150 \mathrm{mg}$ ) cut into three pieces

\begin{tabular}{llc|} 
Experimental group & $\begin{array}{l}\text { Acclimation } \\
\text { (days 1-5) }\end{array}$ & $\begin{array}{c}\text { Treatment } \\
\text { (days 6-20) }\end{array}$ \\
\hline High sugar (control) & $20 \%$ sugar & $20 \%$ sugar \\
\hline Low sugar & $20 \%$ sugar & $1 \%$ sugar \\
\hline High sugar & $20 \%$ sugar & $20 \%$ sugar with \\
+ octopamine & & $4 \mathrm{mg} / \mathrm{ml} \mathrm{OA}$ \\
\hline $\begin{array}{l}\text { Low sugar } \\
+ \text { octopamine }\end{array}$ & $20 \%$ sugar & $1 \%$ sugar with \\
\hline
\end{tabular}

The 20-day experiment was divided into three phases. First, foraging activity was monitored daily as described above during a 5-day acclimation phase before the $\mathrm{OA}$ and sugar treatments onset, to allow experimental colonies to get used to the laboratory environment. Then, after the treatment onset on day 5 , we continued monitoring foraging activity without changing the observational protocol for 10 more days (i.e. exploration phase). We excluded acclimation phase data from the analysis, as well as the first two treatment days of the exploration phase in order to allow experimental treatments to come into effect. There was no major difference in the results of the analysis on foraging activity when using a more stringent cut-off (i.e. removing the first five treatment days instead). We also recorded the time point for which an ant was first counted on the top branch of the artificial tree. During these first 15 days of the experiment, the trees offered no resource and the number of workers counted were considered as a proxy for exploration activity. For the remaining 5 days of the experiment, we placed $0.1 \mathrm{ml}$ of $20 \%$ sugar solution on $a \approx 10 \mathrm{~mm}^{3}$ piece of cotton wool at the top of the tree trunk to measure foraging activity in the context of the exploitation of a novel food source (i.e. exploitation phase). At the time of the assays (i.e. $16 \mathrm{hr}$ after feeding), the sugar reward was the only food source available to the colonies. The time for the first ant to be observed on the top branch of the tree was not analysed for the exploitation phase as the presence of the sugar reward placed on the top of the tree trunk could be considered as a confounding factor. In the majority of trials during the exploitation phase, ants discovered the new food source before the first count 10 minutes after the start of the assay, so we used the number of ants feeding at 10 minutes as a proxy for foraging performance associated with resource discovery.

All analyses were performed in $\mathrm{R}$ ( $\mathrm{R}$ Core Team, 2015). Unless specified otherwise, a significance threshold of 0.05 was used throughout the study. We analysed foraging activity using generalised mixed-effects model (Bates et al., 2017) on the number of workers counted on the tree during the first 20 min of the assay as well as on foraging performance associated with resource discovery. We ran models restricted to experimental phases using region and treatment as fixed effects (interacting if significant) and experimental colony nested within sites as well as observation day as random effects. Effect sizes were given as percentages of the effect for the reference level (i.e. control groups in Argentina), based on the fitted response variable estimates in the GLMMs. To further compare exploration activity, we also performed a series of Cox proportional hazard regression models (Therneau \& Lumley, 2017) on the cumulative probability for the first ant to be observed on the top branch of the tree during the exploration phase, using treatment and region interacting as fixed effects. A consequence of the population bottlenecks associated with the introduction process could be a decrease in behavioural variation along the introduction pathway. To measure this, variance in our main variables-that is exploration and exploitation activity-was compared in control (high sugar) groups among regions with a Fligner-Killeen test for each experimental phase. This test is robust against departure from normality (Teetor, 2011). A significant test was followed by six post hoc pairwise comparisons with 
Bonferroni corrections to adjust the significance threshold for multiple testing and reduce type I error.

\subsection{2 | Interspecific aggression assays}

We performed dyadic interspecific aggression assays between workers to measure the regional differences in Argentine ant aggressiveness as well as the effect of OA and sugar deprivation on aggression. In Argentina and Australia, we selected two species of local Pheidole, a widespread genus that co-occurs with the Argentine ant both in its native and invaded ranges. It was not possible to use the same Pheidole species in the two regions so we chose species with minor workers that are similar in size to L. humile workers (Pheidole triconstricta in Argentina and Pheidole vigilans in Australia). At the end of both the exploration and the exploitation phases (i.e. on Days 15 and 20), a set of eight encounters per experimental colony were performed in small Petri dishes (60 $\mathrm{mm}$ diameter) and filmed from above with a digital camera (Lumix DMC-TZ8, Panasonic). In each Petri dish, we placed one foraging Argentine ant and one Pheidole minor worker, both isolated within plastic cylinders. The inner sides of both the plastic cylinders and the Petri dish were coated with Fluon ${ }^{\circledR}$ to prevent escapes. The cylinders were kept in place for at least one minute to allow the ants to habituate to the environment, and once removed, the interactions between Argentine ant and Pheidole workers were recorded for three minutes. We scored behaviours using a scale ranging from 0 to 4 as follows:

0. Avoidance. Quick change of direction after a contact with the opponent.

1. Neutral. No discernable response after a contact with the opponent.

2. Reactive attack. Bite or use of chemicals after an attack from the opponent.

3. Proactive attack. Proactive bite or use of chemicals on the opponent.

4. Prolonged fight. Continuous aggression for more than $5 \mathrm{~s}$.

Variation in the frequency of Argentine ant interactions among treatments and regions was tested with a cumulative link model with flexible thresholds (Christensen, 2015) using treatment and region as independent variables. "Flexible thresholds" indicate that the model does not assume structured thresholds in the aggression scale. The interaction between treatment and region was included in a first version model but eventually removed, as there was no significant interaction between treatment and region.

\section{3 | RESULTS}

\section{1 | Behavioural variation along the introduction pathway}

In control colonies (high sugar solution, no OA added), we found no consistent differences in behaviour at the regional level in relation to the introduction pathway. There was no significant difference in foraging activity in populations in California (exploration: $b=-0.110$, $z=0.399, p=0.690 ;$ exploitation: $b=0.036, z=0.142, p=0.887$ ) and New Zealand (exploration: $b=0.094, z=0.344, p=0.731$; exploitation: $b=0.130, z=0.511, p=0.610$ ) compared to Argentina. However, experimental colonies in Australia overall exhibited $25 \%$ and $24 \%$ lower foraging activity compared to Argentina in the context of exploration and exploitation activity, respectively (exploration: $b=-0.597, z=-2.157, p=0.031$; Figure 2a, Supporting Information Table S2; exploitation: $b=-0.985, z=-3.822, p<0.001$; Figure $2 b$, Supporting Information Table S3) and were also less likely to reach the top branch of the artificial tree when exploring compared to ants from Argentina $(b=-0.410, z=-2.135, p=0.033$; Supporting Information Table S4). However, we did not find significantly different foraging performance associated with resource discovery in Australia ( $b=-0.318, z=-1.501, p=0.133$ ), but it was $90 \%$ higher in New Zealand compared to Argentina $(b=0.477, z=2.265, p=0.024$; Supporting Information Figure S4, Table S5). We found high variability among collection sites within regions and even among experimental colonies from a single collection site (Figure $2 c$, see variance associated with random effects in Supporting Information Tables S2 and S3), but we found no clear directional change in variance along the pathway. Variance in exploration activity was significantly lower only in Australia compared to California after pairwise comparisons with Bonferroni corrections $\left(\chi^{2}=12.750, d f=1, p<0.001\right.$ ), similar to exploitation activity $\left(\chi^{2}=7.518, d f=1, p=0.006\right.$; Figure 2 , Supporting Information Table S6).

We found higher aggression in Australia compared to Argentina ( $b=0.246, z=5.204, p<0.001$; Figure 3, Supporting Information Table S7), but these results also have to be placed in the context of having used different species of Pheidole in the two regions.

\section{2 | Determinants of foraging activity and aggression}

We found that sugar deprivation did not affect exploration activity, except in California where the effect of sugar deprivation on exploration activity was $20 \%$ lower than in Argentina $(b=-0.589$, $z=-2.253, p=0.024$; Figure 4a, Supporting Information Table S2). However, 13\% more ants were foraging during the exploitation phase in sugar-deprived colonies in Argentina ( $b=0.679, z=3.815$, $p<0.001$ ), and the effect of sugar scarcity was similar in other regions (Figure 4b, Supporting Information Table S3). Sugar deprivation also increased the probability for the first ant to arrive on the top branch in Argentina $(b=0.406, z=2.218, p=0.027$; Figure 5 , Supporting Information Table S4), and the effect was similar in Australia and New Zealand. In California, the pattern was different and sugar-deprived groups were less likely to reach the top branch than control groups $(b=-0.986, z=-3.677, p<0.001$; Figure $5 b$, Supporting Information Table S4). Sugar deprivation increased resource discovery in all regions in a similar fashion, with $147 \%$ more ants feeding at 10 minutes compared to control groups $(b=0.853$, $z=7.111, p<0.001$; Supporting Information Figure S4, Table S5). 


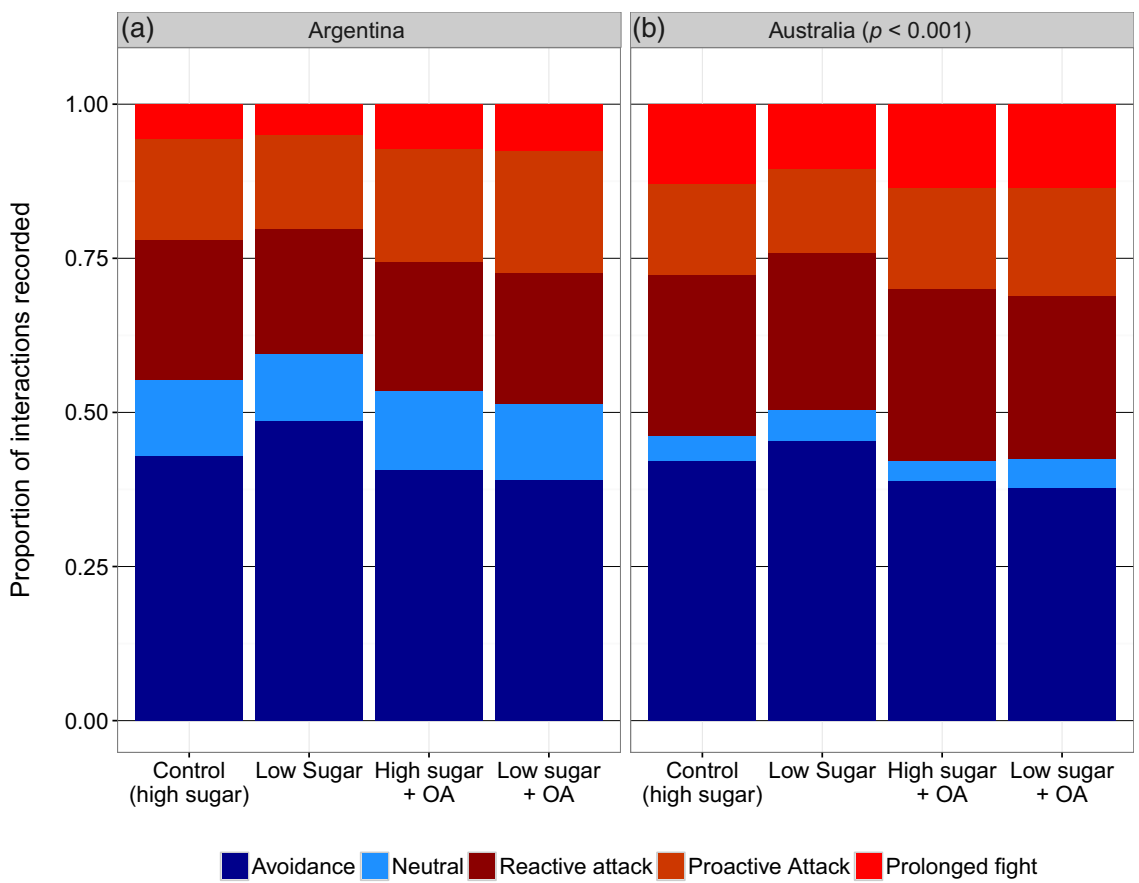

FIGURE 3 Individual Argentine ant aggressiveness towards heterospecific ants was lower in Argentina (a) compared to Australia (b) ( $b=0.246, z=5.204, p<0.001$; Supporting Information Table S7). Experimental treatments modulated Argentine ant interspecific aggression in a similar fashion in the two regions (low sugar: $b=-0.171, z=-2.532, p=0.011$; high sugar + OA: $b=0.126, z=1.879$, $p=0.060$; low sugar + OA: $b=0.176, z=2.584, p=0.010$; Supporting Information Table S7). Sugar deprivation reduced interspecific aggression, and octopamine (OA) supplementation increased aggression when combined with a low sugar diet. Nonaggressive and aggressive interactions are depicted in shades of blue and red, respectively. We performed 128 assays for each treatment in both Argentina and Australia [Colour figure can be viewed at wileyonlinelibrary.com]

HPLC analysis on worker heads revealed that oral OA administration significantly increased OA head titres (Supporting Information Figure S2). OA administration had no statistically significant effects on the levels of tyramine and serotonin $(p=0.279$ and 0.951 , respectively; Supporting Information Figure S5). The median OA head titres were about five times higher than in control groups, but not significantly different between the two OA-treated groups (no difference in post hoc multiple comparison test after Kruskal-Wallis for a threshold of $p=0.05$ ). However, OA-treated colonies combined with low sugar exhibited much higher variance than colonies treated with $\mathrm{OA}$ and high sugar, with some individuals being highly exposed to exogenous OA (Supporting Information Figure S2).

Foraging activity was always higher in OA-treated colonies (Figure 4, Supporting Information Tables S2 and S3). During the exploration phase, both high sugar + OA and low sugar + OA treatments increased foraging activity to a similar extent in all regions, by $26 \%$ and $40 \%$ in Argentina compared to the control treatment, respectively (high sugar + OA: $b=0.800, z=4.377, p<0.001$; low sugar + OA: $b=1.282, z=7.039, p<0.001$; Figure 4a, Supporting Information Table S2). During the exploitation phase, the differences among treatments followed an overall similar trend to that of the exploration phase and in foraging activity were increased by 16 and $20 \%$ relative to control treatment for the high sugar $+O A$ and low sugar $+O A$, respectively (high sugar + OA: $b=0.873, \quad z=4.907, \quad p<0.001 ; \quad$ low sugar + OA: $b=1.115$, $z=6.276, p<0.001$ ), except in Australia where there was a significant positive interaction between region and both $O A$ treatments (high sugar + OA in Australia: $b=0.614, z=2.413, p=0.016$; low sugar + OA in Australia: $b=0.736, z=2.897, p=0.004$; Figure 4b, Supporting Information Table S3). The time for the first ant to be counted on the top branch was also shorter in OA-treated colonies compared to control groups (high sugar + OA: $b=0.449, z=2.462$, $p=0.014 ;$ low sugar + OA: $b=0.877, \quad z=4.798, \quad p<0.001$; Figure 5, Supporting Information Table S4). Both OA treatments increased foraging performance associated with resource discovery in all regions tested relative to the control treatments, by 198 and $257 \%$ for the high sugar $+O A$ and low sugar + OA treatments, respectively (high sugar + OA: $b=1.262, z=10.603, p<0.001$; low sugar + OA: $b=1.825, \quad z=15.434, \quad p<0.001$; Supporting Information Figure S4, Table S5). Sugar-deprived ants displayed less aggressive behaviour than controls $(b=-0.171, z=-2.532$, $p=0.011$ ). We did not find a significant effect of OA supplementation alone on aggression ( $b=0.126, z=1.879, p=0.060)$, but the treatment with sugar-deprived and OA-treated ants showed more aggression than in the control treatment $(b=0.176, z=2.584$, $p=0.010$; Figure 3, Supporting Information Table S7). There was no significant interaction between region and experimental treatment on foraging and aggressive behaviour, indicating that OA administration modulated behaviour in a similar fashion in native and introduced regions. 

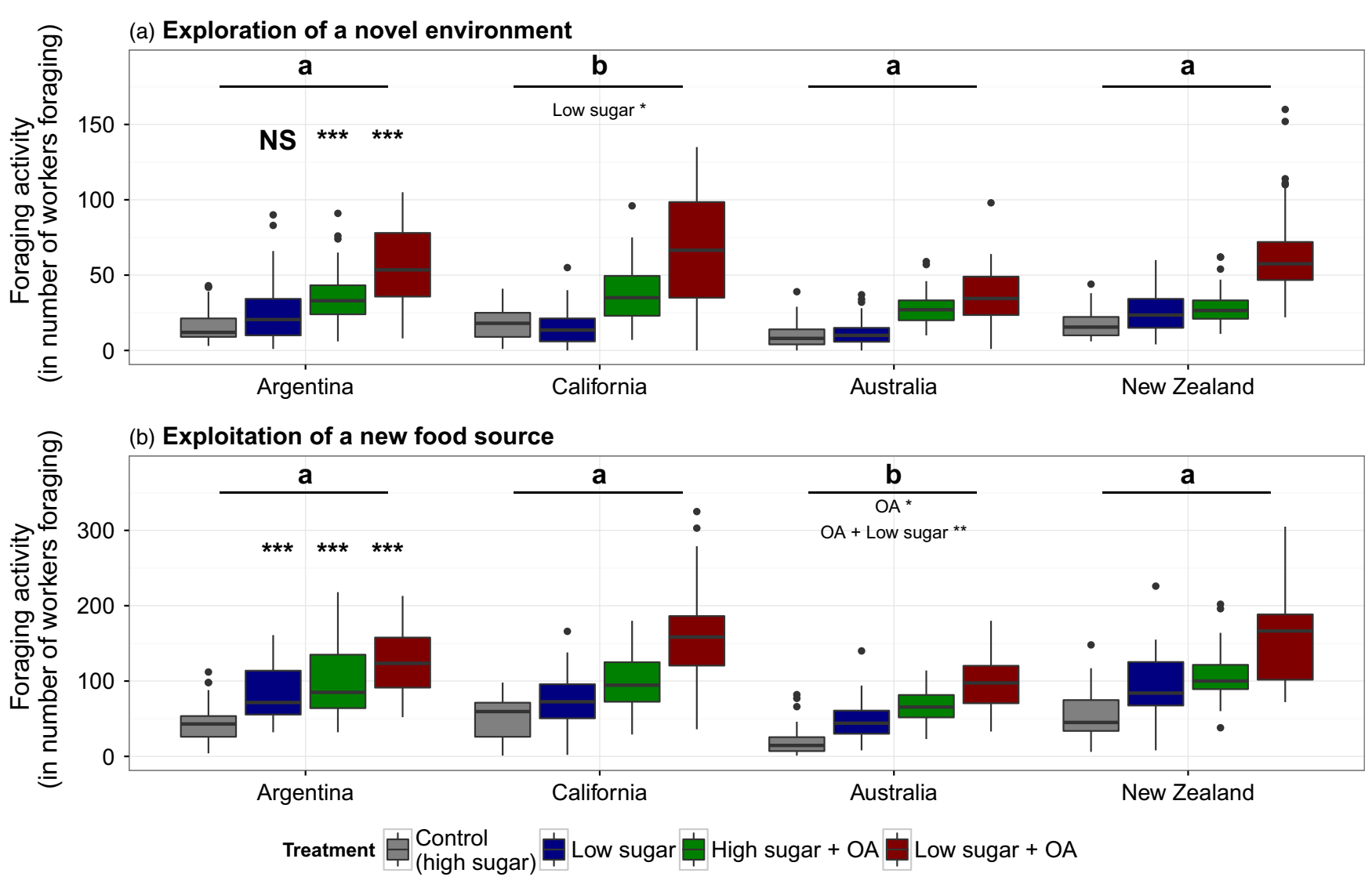

FIGURE 4 Colony-level foraging activity, including exploration activity and exploitation of a food source, was generally increased by our octopamine (OA) treatments. Sugar scarcity only increased foraging activity in the context of the exploitation of a food source. Data are shown as foraging activity $(n=8$ colonies per region, with eight observations for each colony during the exploration phase and five during the exploitation phase) for all treatments during (a) the exploration and (b) the exploitation experimental phases in the native range in Argentina and three invaded regions in California, Australia and New Zealand. Symbolic results of the GLMMs are shown (i.e. ${ }^{* * *}<0.001<{ }^{* *}<0.01<{ }^{*}<0.05<$ NS). The effects of experimental treatments are tested in Argentina, and different letters (i.e. a, b) indicate significant interaction between treatment and region (details of the interaction are given in italics below the corresponding letter). Outliers (i.e. beyond 1.5 interquartile lower and upper ranges) are indicated with black dots. Note the difference in the $y$-axis between the two phases and that data for control groups are also shown in Figure 2 [Colour figure can be viewed at wileyonlinelibrary.com]

\section{4 | DISCUSSION}

We hypothesised that if the introduction process acted as a selective filter for traits that promote invasiveness, Argentine ants would display increased foraging activity and interspecific aggression along an introduction pathway. Although we found considerable variation in behaviour, we did not find a directional response in support of selection on behaviour associated with successive introductions, suggesting that other mechanisms are associated with this variation. We also investigated the potential environmental and physiological basis of foraging behaviour and aggression by manipulating carbohydrate availability and OA supplementation, with the prediction that OA-treated ants would be more exploratory and aggressive, and that sugar scarcity would also affect such behaviours. Our predictions were consistently supported for the effect of OA on foraging activity across both the native and invaded range. The similarity in response to experimental treatments along the introduction pathway suggests that the mechanisms associated with foraging behaviour and aggression are modulated in a similar way in the different populations. Despite successive population bottlenecks that could act as selection filters, our results suggest that behavioural plasticity for responses to variation in carbohydrate availability or OA supplementation was conserved along the introduction pathway.

\section{1 | Behavioural variation along the introduction pathway}

We found no directional variation in colony-level foraging activity that would be consistent with selection on behavioural traits likely to promote invasiveness along the Argentine ant introduction pathway. Our results need to be considered in the context of the various selective forces that may act against each other at different stages of the introduction process. The benefits associated with specific behavioural traits are likely to be context-dependent (Gordon, 2013) and may vary depending on the stage of the introduction process (Chapple \& Wong, 2016; Chapple et al., 2012). Some traits may be regarded as an advantage during some stages of the introduction process, but deleterious in others and may or may not get carried 
to be observed on the top branch of the artificial tree during the exploration phase decreased in all the octopamine-treated groups (OA), but the effect of sugar deprivation differed by region. Data are shown for (a) the native range in Argentina and three invaded regions in (b) California, (c) Australia and (d) New Zealand. Sample size was $n=8$ colonies in each region, with eight observations for each colony. Shaded areas indicate $95 \%$ confidence intervals for the hazard ratio. Symbolic results of the Cox proportional hazard models are shown in each plot and refer to the comparison with controls within region (i.e. ${ }^{* * *}<0.001<{ }^{* *}<0.01<*<0.05<$ NS) [Colour figure can be viewed at wileyonlinelibrary.com] (a) Argentina

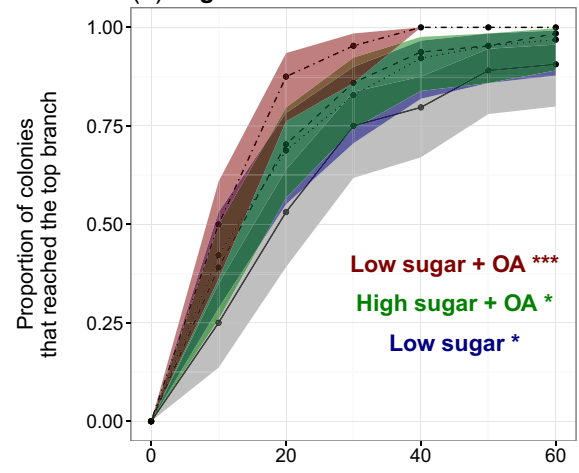

(c) Australia

(b) California

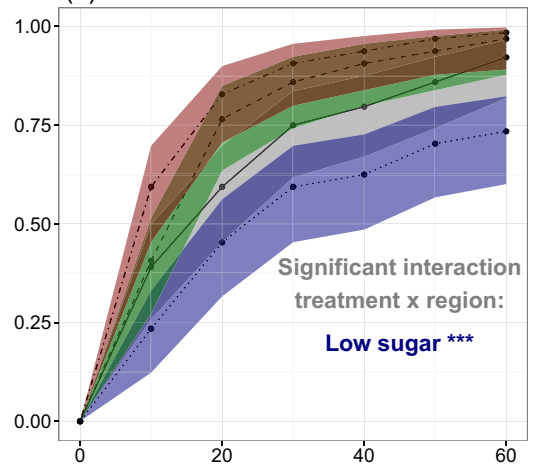

(d) New Zealand

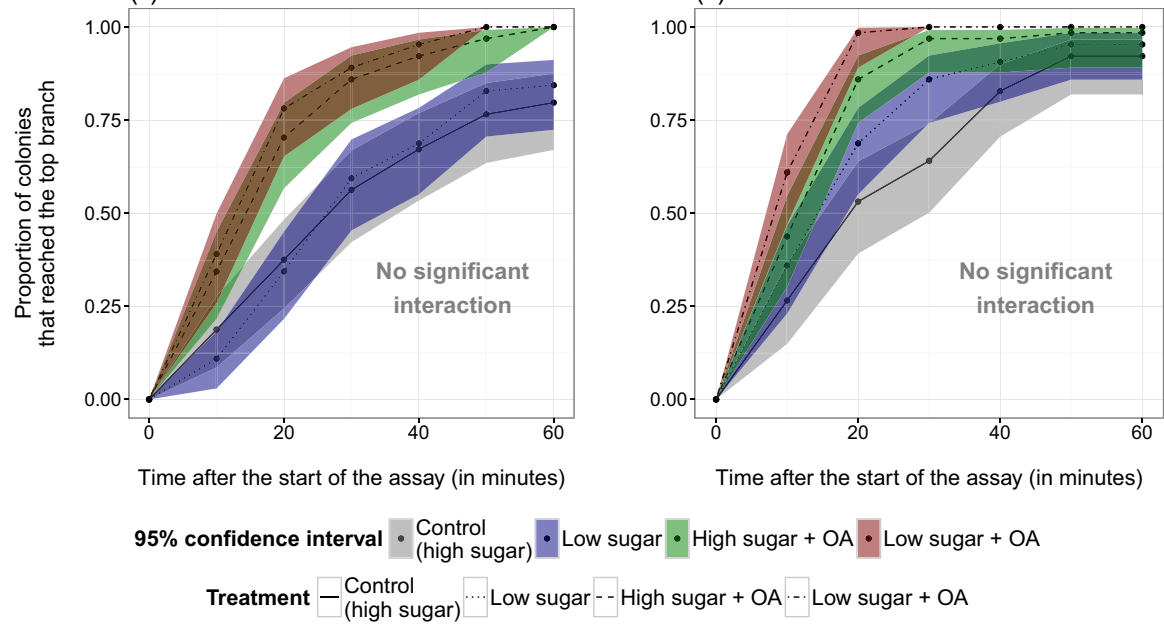

over the subsequent stages of the introduction process. For example, while bold and exploratory behaviours might promote humanmediated dispersal by increasing the chances of uptake on cargo, these traits could also be selected against at other steps along the introduction process (Chapple et al., 2012). Indeed, even though exploratory and aggressive phenotypes may be an advantage in terms of competition in established populations, they may also be risky approaches at early stages of invasion when colony size is likely to be smaller. Interestingly, the Argentine ant does show a behavioural response to colony size, with small nests displaying less aggressive behaviour than bigger ones (Sagata \& Lester, 2009). Behavioural variation within a propagule would therefore be critical for it to successfully invade a new range (Chapple \& Wong, 2016). Selection on behaviour during the introduction process may thus be complex as selective pressures on a given trait may vary along the process.

We found that foraging activity was very variable among sites within region, as well as among experimental colonies within sites. A recent study on another invasive ant, the polygyne form of the red imported fire ant Solenopsis invicta, similarly showed high variability among experimental colonies, even when collected at a single site (Bockoven, Wilder, \& Eubanks, 2015). The causes of such high variability remain unknown and could arise from a variety of factors including colony genetics, environmental factors and colony composition (reviewed in Jandt et al., 2014), and it is known that natural selection can act on such variation (Gordon, 2013; Jandt \& Gordon,
2016). Regardless of the underlying proximate mechanisms, our data suggest that selection could operate to maintain behavioural variation in a similar way throughout the native and invasive ranges. Behavioural variation within a population can persist because different strategies are associated with life-history trade-offs (Biro \& Stamps, 2008) or because of context-dependent consequences of behavioural types on fitness (Lapiedra, Schoener, Leal, Losos, \& Kolbe, 2018; Sih, Bell, Johnson, \& Ziemba, 2004; Smith \& Blumstein, 2008). It is remarkable that, despite serial introductions likely associated with strong population bottlenecks, behavioural variation appears unchanged in introduced populations compared to native ones.

The absence of directional variation in our observations on foraging behaviour along the introduction pathway could also be associated with the foraging strategy of the Argentine ant. The Argentine ant's competitive abilities likely arise from high performance in terms of both exploitation and interference competition. In both field and laboratory studies, the Argentine ant was shown to perform better than native species by discovering and recruiting to food sources more quickly, but also by monopolising these resources (Buczkowski \& Bennett, 2007; Holway, 1999; Human \& Gordon, 1996; Walters \& Mackay, 2005). Numerical advantage appears to be a key component of the foraging success of the Argentine ant, which may thus primarily rely on nest size and connectivity. The nature of the Argentine ant foraging strategy may consequently relax selective pressure on 
foraging activity as we measured it, that is in relatively small and isolated experimental colonies. Interestingly, in its introduced range the Argentine ant exhibits polydomous behaviour (i.e. the formation of networks of interconnected nests) at a much larger scale than in the native range (Pedersen, Krieger, Vogel, Giraud, \& Keller, 2006; Suarez, Tsutsui, Holway, \& Case, 1999; Tsutsui et al., 2000) such that most introduced populations are characterised as "unicolonial." The benefits associated with unicoloniality in terms of foraging may therefore promote ecological dominance in its introduced range, even without increased individual foraging activity.

Moreover, the question of the evolution of worker traits in unicoIonial populations remains unclear. While genetic diversity is lower in colonies in introduced populations relative to colonies in their native range, Argentine ant colonies from introduced populations exhibit low intracolony relatedness when calculating it relative to other individuals within the same supercolony (Pedersen et al., 2006; but see Suarez, Holway, \& Tsutsui, 2008; Tsutsui \& Case, 2001). The Argentine ant worker caste is completely sterile, and hence, low relatedness within supercolonies may imply that selection can no longer operate on worker-specific traits as worker performance does not disproportionately affect the fitness of the queen who produced them (Helanterä, Strassmann, Carrillo, \& Queller, 2009; Queller, 2000; Queller \& Strassmann, 1998). Trait variations in both workers (e.g. foraging behaviour) and queens (e.g. fecundity) are likely to influence the success of a propagule. The short-term success of the propagule in terms of progression along the introduction process would be affected by the behavioural make-up of the propagule, while future spread within a new region would be more affected by the genetic make-up of the queens present in the original propagule who produced new generations of workers. The uncoupling of worker and queen genotypes within propagules and the predicted absence of selection on worker traits in large supercolonies could also explain why no differences in worker foraging behaviour were observed between native and introduced ranges.

We observed more frequent aggressive interactions in Australia compared to Argentina. Our findings are consistent with other reports of the Argentine ant behaving aggressively towards local species in many introduced regions (Buczkowski \& Bennett, 2007; Holway, 1999; Rowles \& O'Dowd, 2006). However, we used two different species of Pheidole in our aggression assays, making comparison among regions potentially confounding. The only study to date that has directly compared foraging behaviour and aggression in native and introduced populations of Argentine ants showed that ants from the main European supercolony were more aggressive and exploratory than ants from native colonies of Argentine ant (Blight et al., 2017). Interestingly, in the same study, Blight et al. (2017) did not find comparable results in ants from the independently introduced Catalonian supercolony. Similarly, different introduced populations in California showed variable frequencies of intraspecific aggression, depending on both the genetic composition of the colony and the identity of the opponent (Tsutsui, Suarez, \& Grosberg, 2003). These two studies do not necessarily support a consistent association between successful introduction and increased interspecific aggression in the Argentine ant. Nevertheless, our results may suggest that invasive Argentine ant populations appear to behave more aggressively than native ones, although more data are needed to provide definite evidence to support this claim.

\subsection{Determinants of behaviour and behavioural plasticity}

We found that sugar-deprived colonies generally reached the top branch of the tree during exploration more quickly than control colonies. They also performed better than control colonies in terms of resource discovery during the exploitation phase, although we did not find any difference in the number of workers exploring. We found higher foraging activity in sugar-deprived colonies during the exploitation phase, which is likely largely due to the nutritional state of the ants by enhancing recruitment to the food source when discovered. We also found an association between carbohydrate scarcity and aggression, with sugar-deprived ants displaying less aggressive behaviour than control ants. Previous studies report evidence for effects of carbohydrate availability on foraging and aggressiveness in ants (Grangier \& Lester, 2014; Grover et al., 2007). Our results provide further evidence for carbohydrate availability as a key determinant of ant foraging behaviour and aggression in the Argentine ant. Carbohydrate availability has been pinpointed as a key feature of invasion success in ants (Helms \& Vinson, 2008; Shik \& Silverman, 2013; Styrsky \& Eubanks, 2007; Wilder, Holway, Suarez, LeBrun, \& Eubanks, 2011), highlighted by differences in resource use between native and introduced populations in the red imported fire ant (Wilder et al., 2011). Interestingly, the behavioural response to carbohydrate scarcity was consistent along the introduction pathway, suggesting that it is a key trait in Argentine ants throughout their native and introduced ranges.

Our dietary treatments showed that OA increased foraging activity at the colony level. These results are also in accordance with previous studies on other social insects, including honeybees and ants, which suggest that $O A$ is associated with forager behavioural traits (Liang et al., 2012; Schulz \& Robinson, 2001; Schulz et al., 2002; Smith et al., 2013; Wagener-Hulme, Kuehn, Schulz, \& Robinson, 1999). OA increases foraging activity in bees in a dose-dependent manner (Schulz \& Robinson, 2001). In our study, the higher exploration activity in colonies treated with OA and deprived of sugar may likewise reflect a dose-dependent effect of OA. Sugar deprivation in the low sugar + OA colonies may be associated with an increase in solution consumption, thereby increasing their exposure to exogenous OA. The OA titration we performed showed increased variance in OA titres in heads, suggesting that some individuals were exposed to higher levels of OA in the low sugar + OA colonies than in any other groups, perhaps driving the increase in colony-level foraging behaviour. However, OA has also been shown to modulate starvation-induced behaviour in Drosophila (Yang et al., 2015), and more experimental work is needed to disentangle a potential interaction between $\mathrm{OA}$ and sugar deprivation in ants. We did not find a significant effect of OA alone on interspecific aggression. However, 
while sugar deprivation alone significantly decreased aggressiveness in Argentine ants, OA combined with low amounts of sugar increased the number of aggressive interactions. OA-modulated aggressive behaviour has been reported in various species of ants (Aonuma \& Watanabe, 2012; Cuvillier-Hot \& Lenoir, 2006; Kamhi et al., 2015; Vander Meer et al., 2008) and appears to perform similar functions in the Argentine ant. Overall, our findings appear to indicate a conserved molecular basis of OA-mediated modulation of foraging behaviour and aggression among social hymenoptera.

We found a consistent effect of our experimental manipulations of sugar availability and OA supplementation on behaviour along the introduction pathway, suggesting no variation in OA signalling between the native and invaded ranges and a conserved response to sugar scarcity. Our results suggest that there was neither loss nor gain of behavioural plasticity along the introduction pathway. Behavioural plasticity has been theorised as a factor in successful adaptation to new environments, especially in early stages of colonisation and before the traits are canalised to a new optimum (Lande, 2015; Wright et al., 2010). Furthermore, there is empirical support for such association between plasticity and ecological success under rapid environmental changes typical of biological invasions in a wide range of animals, spanning from birds to invertebrates (see examples in Chapple \& Wong, 2016). The consistent behavioural responses that we observed after experimental treatments may reflect a broader capacity of introduced Argentine ants to exhibit behavioural plasticity. Our dataset does not include recent introductions, making any assumption on the evolution of plasticity over time difficult. However, our study does suggest that mechanisms maintained behavioural plasticity in the introduced range, despite numerous serial introduction events likely associated with population bottlenecks.

Overall, we observed consistent colony-level foraging activity along the Argentine ant's introduction pathway, as well as behavioural plasticity in response to diet variation and neurohormone supplementation. It appears that successive introductions did not result in strong selection on behavioural traits often associated with invasion success. Our results challenge the assumption that invasive populations always outperform native populations in some of the key behavioural traits associated with invasion success (e.g. increased aggression or foraging activity). We also did not find support for the hypothesis that the process of invasion acts as a filter, with no evidence for strong selection on behaviour that may facilitate further introductions. Instead of adaptive evolution, it is likely that factors such as increased abundance in introduced range combined with ease of human-mediated transport play a large part in the Argentine ant's invasion success (Bertelsmeier \& Keller, 2018; Bertelsmeier, Ollier, Liebhold, \& Keller, 2017; Bertelsmeier et al., 2018; Suarez, Holway, \& Case, 2001). However, an investigation of other behavioural traits such as social organisation or a more extensive survey of interspecific aggression in relation to the introduction pathway would complement the focus on foraging and exploratory behaviour in this study. We encourage further testing of the hypothesis in other systems to better understand interactions between the introduction of exotic species and evolution of their invasiveness.

\section{ACKNOWLEDGEMENTS}

We thank Bradley de Abreu, Priscila Hanisch and Romain Felden for their help in the field in New Zealand, Argentina and Australia, respectively. We also thank three anonymous referees for their helpful suggestions, the Lester Lab at Victoria University of Wellington and the Tsutsui Lab at UC-Berkeley for valuable advice and support. Our research was funded by Royal Society of New Zealand Marsden Grant 13-VUW-038 to Monica Gruber.

\section{AUTHORS' CONTRIBUTIONS}

A.F., M.A.M.G. and P.J.L. conceived the study. A.F. performed field collection, with the help of A.V.S. and C.P. in Argentina. A.F. performed the experimental work, supported by C.P., D.G.C. and N.D.T. A.F. analysed the data, with statistical advice from J.H. A.F. led the writing of the manuscript, and all authors contributed critically to the drafts and gave final approval for publication.

\section{DATA ACCESSIBILITY}

All data and R scripts required for the analyses and plotting are available as csv and R documents on GitHub at https://doi.org/10.5281/ zenodo.1306314 (Felden, 2018).

\section{ORCID}

Antoine Felden (iD http://orcid.org/0000-0002-8499-0739

Carolina I. Paris (iD http://orcid.org/0000-0001-7582-0546

David G. Chapple (iD http://orcid.org/0000-0002-7720-6280

Andrew V. Suarez (iD http://orcid.org/0000-0002-2257-3366

Neil D. Tsutsui iD http://orcid.org/0000-0002-1868-3941

Philip J. Lester iD http://orcid.org/0000-0002-1801-5687

Monica A. M. Gruber (iD http://orcid.org/0000-0001-6780-8838

\section{REFERENCES}

Allendorf, F. W., \& Lundquist, L. L. (2003). Introduction: Population biology, evolution, and control of invasive species. Conservation Biology, 17, 24-30. https://doi.org/10.1046/j.1523-1739.2003.02365.x

Aonuma, H., \& Watanabe, T. (2012). Octopaminergic system in the brain controls aggressive motivation in the ant, Formica Japonica. Acta Biologica Hungarica, 63, 63-68. https://doi.org/10.1556/ABiol. 63.2012.Suppl.2.6

Barron, A. B., Maleszka, J., Vander Meer, R. K., Robinson, G. E., \& Maleszka, R. (2007). Comparing injection, feeding and topical application methods for treatment of honeybees with octopamine. Journal of Insect Physiology, 53, 187-194. https://doi.org/10.1016/j. jinsphys.2006.11.009

Bates, D., Maechler, M., Bolker, B., Walker, S., Christensen, R. H. B., Singmann, H., ... Green, P.. (2017). Ime4: Linear Mixed-Effects Models using "Eigen" and $\mathrm{S} 4$.

Bertelsmeier, C., \& Keller, L. (2018). Bridgehead effects and role of adaptive evolution in invasive populations. Trends in Ecology \& Evolution, 33, 527-534. https://doi.org/10.1016/j.tree.2018.04.014 
Bertelsmeier, C., Ollier, S., Liebhold, A. M., Brockerhoff, E. G., Ward, D., \& Keller, L. (2018). Recurrent bridgehead effects accelerate global alien ant spread. Proceedings of the National Academy of Sciences of the United States of America, 115, 5486-5491. https://doi.org/10.1073/ pnas.1801990115

Bertelsmeier, C., Ollier, S., Liebhold, A., \& Keller, L. (2017). Recent human history governs global ant invasion dynamics. Nature Ecology \& Evolution, 1, 0184. https://doi.org/10.1038/s41559-017-0184

Biro, P. A., \& Stamps, J. A. (2008). Are animal personality traits linked to life-history productivity? Trends in Ecology \& Evolution, 23, 361-368. https://doi.org/10.1016/j.tree.2008.04.003

Blackburn, T. M., Pyšek, P., Bacher, S., Carlton, J. T., Duncan, R. P., Jarošík, V., ... Richardson, D. M. (2011). A proposed unified framework for biological invasions. Trends in Ecology \& Evolution, 26, 333-339. https:// doi.org/10.1016/j.tree.2011.03.023

Blight, O., Josens, R., Bertelsmeier, C., Abril, S., Boulay, R., \& Cerdá, X. (2017). Differences in behavioural traits among native and introduced colonies of an invasive ant. Biological Invasions, 19(1389), 1-10. https://doi.org/10.1007/s10530-016-1353-5

Bockoven, A. A., Wilder, S. M., \& Eubanks, M. D. (2015). Intraspecific variation among social insect colonies: Persistent regional and colony-level differences in fire ant foraging behavior. PLoS ONE, 10, e0133868. https://doi.org/10.1371/journal.pone.0133868

Buczkowski, G., \& Bennett, G. W. (2007). Aggressive interactions between the introduced Argentine ant, Linepithema humile and the native odorous house ant, Tapinoma sessile. Biological Invasions, 10, 1001-1011. https://doi.org/10.1007/s10530-007-9179-9

Chapple, D. G., Simmonds, S. M., \& Wong, B. B. (2011). Know when to run, know when to hide: Can behavioral differences explain the divergent invasion success of two sympatric lizards? Ecology and Evolution, 1, 278-289. https://doi.org/10.1002/ece3.22

Chapple, D. G., Simmonds, S. M., \& Wong, B. B. M. (2012). Can behavioral and personality traits influence the success of unintentional species introductions? Trends in Ecology \& Evolution, 27, 57-64. https://doi. org/10.1016/j.tree.2011.09.010

Chapple, D. G., \& Wong, B. B. (2016). The role of behavioural variation across different stages of the introduction process. In J. S. Weis \& D. Sol (Eds.), Biological invasions and animal behaviour (pp. 7-25). Cambridge, UK: Cambridge University Press. https://doi. org/10.1017/CBO9781139939492

Christensen, R. H. B. (2015). Ordinal: Regression models for ordinal data.

Corin, S. E., Lester, P. J., Abbott, K. L., \& Ritchie, P. A. (2007). Inferring historical introduction pathways with mitochondrial DNA: The case of introduced Argentine ants (Linepithema humile) into New Zealand: Inferring introduction pathways. Diversity and Distributions, 13, 510518. https://doi.org/10.1111/j.1472-4642.2007.00355.x

Cuvillier-Hot, V., \& Lenoir, A. (2006). Biogenic amine levels, reproduction and social dominance in the queenless ant Streblognathus peetersi. Naturwissenschaften, 93, 149-153. https://doi.org/10.1007/ s00114-006-0086-1

Dlugosch, K. M., \& Parker, I. M. (2008). Founding events in species invasions: Genetic variation, adaptive evolution, and the role of multiple introductions. Molecular Ecology, 17, 431-449. https://doi. org/10.1111/j.1365-294X.2007.03538.x

Felden, A. (2018). Antoinefelden/journal_of_animal_ecology_2018: Initial release for publication (Version 1.1). Zenodo. https://doi.org/10.5281/ zenodo.1306315

Gordon, D. M. (2013). The rewards of restraint in the collective regulation of foraging by harvester ant colonies. Nature, 498, 91-93. https://doi.org/10.1038/nature12137

Grangier, J., \& Lester, P. J. (2014). Carbohydrate scarcity increases foraging activities and aggressiveness in the ant Prolasius advenus (Hymenoptera: Formicidae): Influence of diet composition on ant behaviour. Ecological Entomology, 39, 684-692. https://doi. org/10.1111/een.12146
Grover, C. D., Kay, A. D., Monson, J. A., Marsh, T. C., \& Holway, D. A. (2007). Linking nutrition and behavioural dominance: Carbohydrate scarcity limits aggression and activity in Argentine ants. Proceedings of the Royal Society B: Biological Sciences, 274, 2951-2957. https://doi. org/10.1098/rspb.2007.1065

Helanterä, H., Strassmann, J. E., Carrillo, J., \& Queller, D. C. (2009). Unicolonial ants: Where do they come from, what are they and where are they going? Trends in Ecology \& Evolution, 24, 341-349. https://doi. org/10.1016/j.tree.2009.01.013

Helms, K. R., \& Vinson, S. B. (2008). Plant resources and colony growth in an invasive ant: The importance of honeydew-producing hemiptera in carbohydrate transfer across trophic levels. Environmental Entomology, 37, 487-493. https://doi.org/10.1093/ee/37.2.487

Holway, D. A. (1999). Competitive mechanisms underlying the displacement of native ants by the invasive Argentine ant. Ecology, 80, 238-251. https:// doi.org/10.1890/0012-9658(1999)080[0238:CMUTDO]2.0.CO;2

Holway, D. A., Lach, L., Suarez, A. V., Tsutsui, N. D., \& Case, T. J. (2002). The causes and consequences of ant invasions. Annual Review of Ecology and Systematics, 33, 181-233. https://doi.org/10.1146/ annurev.ecolsys.33.010802.150444

Holway, D. A., \& Suarez, A. V. (1999). Animal behavior: An essential component of invasion biology. Trends in Ecology \& Evolution, 14, 328330. https://doi.org/10.1016/S0169-5347(99)01636-5

Human, K. G., \& Gordon, D. M. (1996). Exploitation and interference competition between the invasive Argentine ant, Linepithema humile, and native ant species. Oecologia, 105, 405-412. https://doi. org/10.1007/BF00328744

Jandt, J. M., Bengston, S., Pinter-Wollman, N., Pruitt, J. N., Raine, N. E., Dornhaus, A., \& Sih, A. (2014). Behavioural syndromes and social insects: Personality at multiple levels. Biological Reviews, 89, 48-67. https://doi.org/10.1111/brv.12042

Jandt, J., \& Gordon, D. (2016). The behavioral ecology of variation in social insects. Current Opinion in Insect Science, 15, 40-44. https://doi. $\operatorname{org} / 10.1016 /$ j.cois.2016.02.012

Kamhi, J. F., Arganda, S., Moreau, C. S., \& Traniello, J. F. A. (2017). Origins of aminergic regulation of behavior in complex insect social systems. Frontiers in Systems Neuroscience, 11, 74. https://doi.org/10.3389/ fnsys.2017.00074

Kamhi, J. F., Nunn, K., Robson, S. K. A., \& Traniello, J. F. A. (2015). Polymorphism and division of labour in a socially complex ant: Neuromodulation of aggression in the Australian weaver ant, Oecophylla smaragdina. Proceedings of the Royal Society B: Biological Sciences, 282, 20150704. https://doi.org/10.1098/rspb.2015.0704

Kolar, C. S., \& Lodge, D. M. (2001). Progress in invasion biology: Predicting invaders. Trends in Ecology \& Evolution, 16, 199-204. https://doi. org/10.1016/S0169-5347(01)02101-2

Lande, R. (2015). Evolution of phenotypic plasticity in colonizing species. Molecular Ecology, 24, 2038-2045. https://doi.org/10.1111/ mec.13037

Lapiedra, O., Schoener, T. W., Leal, M., Losos, J. B., \& Kolbe, J. J. (2018). Predator-driven natural selection on risk-taking behavior in anole lizards. Science, 360, 1017-1020. https://doi.org/10.1126/science. aap9289

Liang, Z. S., Nguyen, T., Mattila, H. R., Rodriguez-Zas, S. L., Seeley, T. D., \& Robinson, G. E. (2012). Molecular determinants of scouting behavior in honey bees. Science, 335, 1225-1228. https://doi.org/10.1126/ science.1213962

Parker, J. D., Torchin, M. E., Hufbauer, R. A., Lemoine, N. P., Alba, C., Blumenthal, D. M., ... Wolfe, L. M. (2013). Do invasive species perform better in their new ranges? Ecology, 94, 985-994. https://doi. org/10.1890/12-1810.1

Pedersen, J.S., Krieger, M. J., Vogel, V., Giraud, T., \& Keller, L. (2006). Native supercolonies of unrelated individuals in the invasive Argentine ant. Evolution, 60, 782-791. https://doi.org/10.1111/j.0014-3820.2006. tb01156.x 
Phillips, B. L., \& Suarez, A. V. (2012). The role of behavioural variation in the invasion of new areas. Behavioural responses to a changing world. Oxford, UK: Oxford University Press.

Queller, D. C. (2000). Pax argentinica. Nature, 405, 519-520. https://doi. org/10.1038/35014705

Queller, D. C., \& Strassmann, J. E. (1998). Kin selection and social insects: Social insects provide the most surprising predictions and satisfying tests of kin selection. BioScience, 48, 165-175. https://doi. org/10.2307/1313262

R Core Team. (2015). R: A language and environment for statistical computing. Vienna, Austria: R Foundation for Statistical Computing.

Rowles, A. D., \& O'Dowd, D. J. (2006). Interference competition by Argentine ants displaces native ants: Implications for biotic resistance to invasion. Biological Invasions, 9, 73-85. https://doi.org/10.1007/ s10530-006-9009-5

Sagata, K., \& Lester, P. J. (2009). Behavioural plasticity associated with propagule size, resources, and the invasion success of the Argentine ant Linepithema humile. Journal of Applied Ecology, 46, 19-27. https:// doi.org/10.1111/j.1365-2664.2008.01523.x

Sakai, A. K., Allendorf, F. W., Holt, J. S., Lodge, D. M., Molofsky, J., With, K. A., ... Weller, S. G. (2001). The population biology of invasive species. Annual Review of Ecology and Systematics, 32, 305-332. https:// doi.org/10.1146/annurev.ecolsys.32.081501.114037

Sax, D. F., \& Brown, J. H. (2000). The paradox of invasion. Global Ecology and Biogeography, 9, 363-371. https://doi. $\operatorname{org} / 10.1046 / j .1365-2699.2000 .00217 . x$

Scholes, D. R., \& Suarez, A. V. (2009). Speed-versus-accuracy tradeoffs during nest relocation in Argentine ants (Linepithema humile) and odorous house ants (Tapinoma sessile). Insectes Sociaux, 56, 413. https://doi.org/10.1007/s00040-009-0039-8

Schulz, D. J., Barron, A. B., \& Robinson, G. E. (2002). A role for octopamine in honey bee division of labor. Brain, Behavior and Evolution, 60, 350-359. https://doi.org/10.1159/000067788

Schulz, D. J., \& Robinson, G. E. (2001). Octopamine influences division of labor in honey bee colonies. Journal of Comparative Physiology A, 187, 53-61. https://doi.org/10.1007/s003590000177

Seid, M. A., \& Traniello, J. F. A. (2005). Age-related changes in biogenic amines in individual brains of the ant Pheidole dentata. Naturwissenschaften, 92, 198-201. https://doi.org/10.1007/ s00114-005-0610-8

Shik, J. Z., \& Silverman, J. (2013). Towards a nutritional ecology of invasive establishment: Aphid mutualists provide better fuel for incipient Argentine ant colonies than insect prey. Biological Invasions, 15, 829-836. https://doi.org/10.1007/s10530-012-0330-x

Sih, A., Bell, A. M., Johnson, J. C., \& Ziemba, R. E. (2004). Behavioral syndromes: An integrative overview. The Quarterly Review of Biology, 79, 241-277. https://doi.org/10.1086/422893

Smith, B. R., \& Blumstein, D. T. (2008). Fitness consequences of personality: A meta-analysis. Behavioral Ecology, 19, 448-455. https://doi. org/10.1093/beheco/arm144

Smith, A. R., Muscedere, M. L., Seid, M. A., Traniello, J. F. A., \& Hughes, W. O. H. (2013). Biogenic amines are associated with worker task but not patriline in the leaf-cutting ant Acromyrmex echinatior. Journal of Comparative Physiology A, 199, 1117-1127. https://doi.org/10.1007/ s00359-013-0854-2

Styrsky, J. D., \& Eubanks, M. D. (2007). Ecological consequences of interactions between ants and honeydew-producing insects. Proceedings of the Royal Society of London B: Biological Sciences, 274, 151-164. https://doi.org/10.1098/rspb.2006.3701

Suarez, A. V., Holway, D. A., \& Case, T. J. (2001). Patterns of spread in biological invasions dominated by long-distance jump dispersal: Insights from Argentine ants. Proceedings of the National Academy of Sciences of the United States of America, 98, 1095-1100. https://doi. org/10.1073/pnas.98.3.1095
Suarez, A. V., Holway, D. A., \& Tsutsui, N. D. (2008). Genetics and behavior of a colonizing species: The invasive Argentine ant. The American Naturalist, 172, S72-S84. https://doi.org/10.1086/588638

Suarez, A. V., \& Tsutsui, N. D. (2008). The evolutionary consequences of biological invasions. Molecular Ecology, 17, 351-360. https://doi. org/10.1111/j.1365-294X.2007.03456.x

Suarez, A. V., Tsutsui, N. D., Holway, D. A., \& Case, T. J. (1999). Behavioral and genetic differentiation between native and introduced populations of the Argentine ant. Biological Invasions, 1, 43-53. https://doi. org/10.1023/A:1010038413690

Suhr, E. L., O'Dowd, D. J., McKechnie, S. W., \& Mackay, D. A. (2011). Genetic structure, behaviour and invasion history of the Argentine ant supercolony in Australia. Evolutionary Applications, 4, 471-484. https://doi.org/10.1111/j.1752-4571.2010.00161.x

Teetor, P. (2011). R Cookbook. O'Reilly.

Therneau, T. M., \& Lumley, T. (2017). Survival: Survival analysis.

Torchin, M. E., Lafferty, K. D., Dobson, A. P., McKenzie, V. J., \& Kuris, A. M. (2003). Introduced species and their missing parasites. Nature, 421, 628-630. https://doi.org/10.1038/nature01346

Tsutsui, N. D., \& Case, T. J. (2001). Population genetics and colony structure of the Argentine ant (Linepithema humile) in its native and introduced range. Evolution, 55, 976. https://doi.org/10.1554/00143820(2001) 055[0976:PGACSO]2.0.CO;2

Tsutsui, N. D., Suarez, A. V., \& Grosberg, R. K. (2003). Genetic diversity, asymmetrical aggression, and recognition in a widespread invasive species. Proceedings of the National Academy of Sciences of the United States of America, 100, 1078-1083. https://doi.org/10.1073/pnas.0234412100

Tsutsui, N. D., Suarez, A. V., Holway, D. A., \& Case, T. J. (2000). Reduced genetic variation and the success of an invasive species. Proceedings of the National Academy of Sciences of the United States of America, 97, 5948-5953. https://doi.org/10.1073/pnas.100110397

Tsutsui, N. D., Suarez, A. V., Holway, D. A., \& Case, T. J. (2001). Relationships among native and introduced populations of the Argentine ant (Linepithema humile) and the source of introduced populations. Molecular Ecology, 10, 2151-2161. https://doi. org/10.1046/j.0962-1083.2001.01363.x

Van Wilgenburg, E., Torres, C. W., \& Tsutsui, N. D. (2010). The global expansion of a single ant supercolony: A transcontinental Argentine ant supercolony. Evolutionary Applications, 3, 136-143. https://doi. org/10.1111/j.1752-4571.2009.00114.x

Vander Meer, R. K., Preston, C. A., \& Hefetz, A. (2008). Queen regulates biogenic amine level and nestmate recognition in workers of the fire ant, Solenopsis invicta. Naturwissenschaften, 95, 1155-1158. https:// doi.org/10.1007/s00114-008-0432-6

Vogel, V., Pedersen, J. S., Giraud, T., Krieger, M. J. B., \& Keller, L. (2010). The worldwide expansion of the Argentine ant. Diversity and Distributions, 16, 170-186. https://doi.org/10.1111/j.1472-4642.2009.00630.x

Wagener-Hulme, C., Kuehn, J. C., Schulz, D. J., \& Robinson, G. E. (1999). Biogenic amines and division of labor in honey bee colonies. Journal of Comparative Physiology A, 184, 471-479. https://doi.org/10.1007/ s003590050347

Walters, A. C., \& Mackay, D. A. (2005). Importance of large colony size for successful invasion by Argentine ants (Hymenoptera: Formicidae): Evidence for biotic resistance by native ants. Austral Ecology, 30, 395-406. https://doi.org/10.1111/j.1442-9993.2005.01481.x

Wetterer, J. K., Wild, A. L., Suarez, A. V., Roura-Pascual, N., \& Espadaler, X. (2009). Worldwide spread of the Argentine ant, Linepithema humile (Hymenoptera: Formicidae). Myrmecological News, 12, 187-194.

Whitney, K. D., \& Gabler, C. A. (2008). Rapid evolution in introduced species, "invasive traits" and recipient communities: Challenges for predicting invasive potential. Diversity and Distributions, 14, 569-580. https://doi.org/10.1111/j.1472-4642.2008.00473.x

Wilder, S. M., Holway, D. A., Suarez, A. V., LeBrun, E. G., \& Eubanks, M. D. (2011). Intercontinental differences in resource use reveal the 
importance of mutualisms in fire ant invasions. Proceedings of the National Academy of Sciences of the United States of America, 108, 20639-20644. https://doi.org/10.1073/pnas.1115263108

Wright, T. F., Eberhard, J. R., Hobson, E. A., Avery, M. L., \& Russello, M. A. (2010). Behavioral flexibility and species invasions: The adaptive flexibility hypothesis. Ethology Ecology \& Evolution, 22, 393-404. https://doi.org/10.1080/03949370.2010.505580

Yang, Z., Yu, Y., Zhang, V., Tian, Y., Qi, W., \& Wang, L. (2015). Octopamine mediates starvation-induced hyperactivity in adult Drosophila. Proceedings of the National Academy of Sciences of the United States of America, 112, 5219-5224. https://doi.org/10.1073/ pnas.1417838112

\section{SUPPORTING INFORMATION}

Additional supporting information may be found online in the Supporting Information section at the end of the article.

How to cite this article: Felden A, Paris $\mathrm{Cl}$, Chapple DG, et al. Behavioural variation and plasticity along an invasive ant introduction pathway. J Anim Ecol. 2018;87:1653-1666.

https://doi.org/10.1111/1365-2656.12886 